\title{
JCOM \\ Telling it straight - a focus group study on narratives affecting public confidence in science
}

\section{Fredrik Brounéus, Maria Lindholm and Gustav Bohlin}

\begin{abstract}
Public confidence in research is important for scientific results to achieve societal impact. Swedish surveys suggest consistent but differing levels of confidence in different research areas. Thus, certain research-related factors can be assumed to have a decisive influence on confidence levels. This focus-group study explores the role of different narratives in shaping public confidence in research. Findings include four themes with potential to increase or decrease public confidence: Person, Process, Product and Presentation. The results offer insights as to how public confidence in research is formed and may give researchers agency in promoting confidence through their communication activities.
\end{abstract}

Keywords

Public perception of science and technology; Public understanding of science and technology; Representations of science and technology

DOI

https://doi.org/10.22323/2.18050203

Submitted: 8th March 2019

Accepted: 12th August 2019

Published: 14th October 2019

Context

To gain knowledge in any area or aspect, people of all ages and societal contexts depend on information from others. However, for people to accept the information, the source needs to be trusted [Sperber et al., 2010]. With regard to what determines such trust, several sets of dimensions have previously been described. Examples include the three determinants Knowledge $\mathcal{E}$ expertise, Openness $\mathcal{E}$ honesty, and Concern $\mathcal{E}$ care [Peters, Covello and McCallum, 1997]; the Competence, Care and Consensual values dimensions [Johnson, 1999]; and Expertise, Integrity, and Benevolence [Hendriks, Kienhues and Bromme, 2015].

The issues of public confidence in science and researchers are continuously relevant topics that are receiving scholarly attention [e.g. Gauchat, 2012; Dierkes and von Grote, 2005]. Resnik [2011, p. 1] writes that: "The idea that it is important to promote public trust in scientific research has been used by so many different authors in so many different contexts that it is in danger of becoming a platitude". Even though there are several understandings of the concept, the importance of promoting confidence in researchers is widely agreed. The relevance of fostering 
public confidence in researchers can be illustrated by findings suggesting that this trust influences the link between knowledge and concern about global warming [Malka, Krosnick and Langer, 2009].

While trust and confidence are often used synonymously in many contexts, certain differences have been pointed out. In his distinction between the two, Luhmann concurs that both concepts "refer to expectations which may lapse into disappointment" [Luhmann, 2000, p. 97], but argues that the concepts differ with regard to perception and attribution. If we make a choice where we take different alternatives into account, it is a matter of trust. When we take a course of action without previous reflection on alternatives, we rely on our confidence in the matter [Luhmann, 2000]. Public attitudes towards research and researchers can concern trust as well as confidence, but as the Swedish word "förtroende" — which was used in the Swedish public surveys described below, as well as in the focus groups of the present study - can describe either of the two, for reasons of simplicity we only use "confidence" when describing our results.

Public levels of confidence toward science and researchers has been the subject of several national and international studies [e.g. Gallup, 2019]. In Sweden, public surveys on confidence in research and researchers have been performed annually since 2002. In general, the results indicate high levels of confidence, with small fluctuations over time [Vetenskap \& Allmänhet, 2019b]. Equally consistent, however, is the presence of large differences in confidence towards different scientific fields (Figure 1). Medical sciences have the highest confidence levels and the humanities have the lowest. And while the surveys have identified age, education level and area of residence to be important explanatory factors, where younger, more educated people living in urban areas exhibit higher confidence levels in general, compared to older and less educated peoples living in less populated areas, these factors offer no explanations to the differences in confidence between scientific fields.
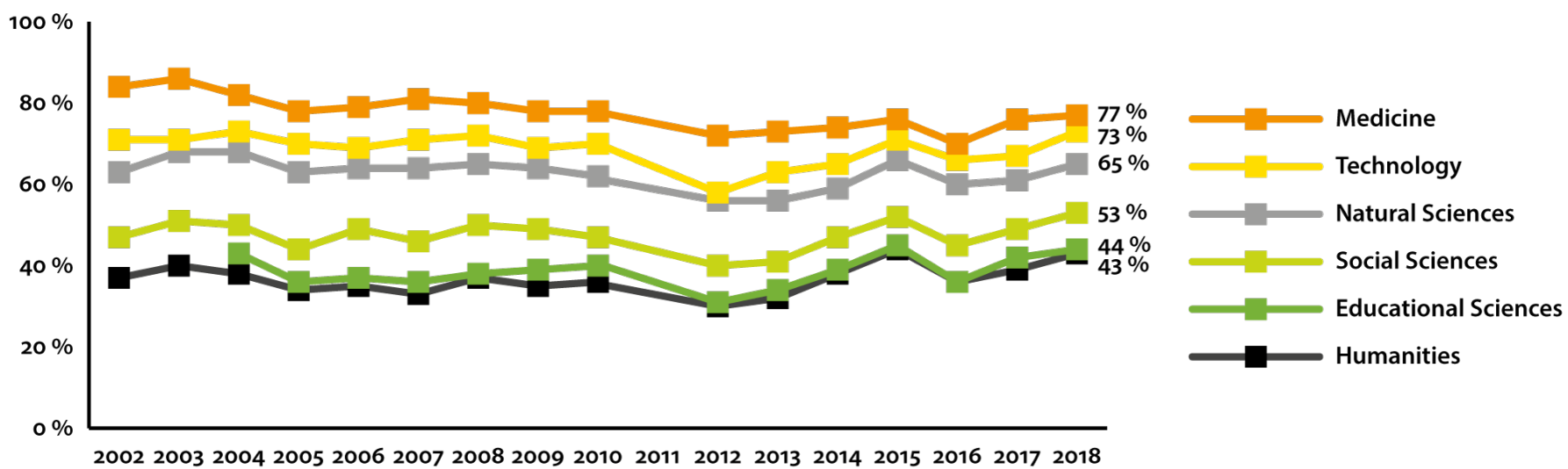

Figure 1. Confidence in different research areas among the Swedish public 2002-2017. Lines indicate proportions with fairly or very high confidence $(n=1771)$ [Vetenskap \& Allmänhet, 2019b].

In international comparison, the Swedish survey results do not seem to differ radically from those of other countries. For instance, the observation that different socio-demographic groups differ in their confidence towards science is made in several countries [e.g. Castell et al., 2014; Lakomý et al., 2018]. This finding has led to novel strategies to better understand public confidence in science. One of these is 
based on segmentation analysis, where the respondents are grouped based on other factors than demographics, such as "psychographics" and media use [Füchslin, Schäfer and Metag, 2018; Schäfer et al., 2018]. Yet, no conclusions can be drawn from the surveys as to why certain research fields inspire higher or lower confidence levels or how this could be influenced.

Some would possibly argue that it is a question of knowledge. However, this assumption, that positive attitudes towards science should follow automatically from increased knowledge, the so-called deficit model, has been repeatedly questioned, with the link between knowledge and attitudes seeming very weak [e.g. Allum et al., 2008]. Rather, a person's attitudes seem to be based on a multitude of cultural factors, including political views [Kahan, Jenkins-Smith and Braman, 2011]. In this regard, the roles of narrative and storytelling have received an increased interest in the context of shaping public attitudes and confidence in science [e.g. Dahlstrom, 2014].

Although no universal definition of "narrative" has been agreed upon by researchers, a fundamental characteristic is that it concerns a sharing of information through the telling of stories [e.g. Hinyard and Kreuter, 2007]. As such, narratives provide a vehicle for conveying knowledge about scientific concepts or procedures. Compared to more traditional formats for science communication, narratives may offer increased comprehension and interest [Dahlstrom, 2014]. Non-academic audiences receive most of their information about science through the mass media, which usually present this information through narratives. It has also been suggested that narratives play a significant role in our cognitive understanding and meaning-making of the world [e.g. Goodson et al., 2010; Jones and Song, 2013].

In his synthesis of literature on the role of narrative and storytelling in science communication, Dahlstrom [2014], identifies several themes of interest for public trust. Stories are said to have the potential both to increase trust, due to their appearance of authenticity, and to decrease trust levels, due to being overly sensational. On the whole, it is concluded that there is a need for more studies in the area as: "the influence of narratives within a trust context remains unknown" [Dahlstrom, 2014, p. 13618].

In focus groups and interviews with researchers, Felt and Fochler [2013] explored narratives from the researchers' perspective. Among the findings were that the interviewees were critical towards the narrative of scientific practice as being continuously exciting and successful, as this creates social expectations based on a false representation of science. It was also acknowledged that researchers themselves contributed to this narrative in how they portrayed their practice in, for example, grant applications [Felt and Fochler, 2013]. These results are corroborated by Master and Resnik [2013], who note that hyping research results may impact public confidence negatively [Master and Resnik, 2013].

Stories and narratives may offer a powerful vehicle for affecting a person's attitudes towards science and research. Since they seem to enable both increases and decreases in confidence depending on a number of factors, it is of high interest to explore which narratives are currently dominant in shaping public confidence in science. 
The primary aim of this study was to gain insight into what narratives people use to justify their confidence in research, and whether these narratives or stories could be identified as increasing or lowering their confidence. No measures were taken with an intention to affect the confidence levels among the participants.

\section{Methods}

Focus groups were considered a relevant method as we predicted that the narratives that we were interested in capturing were more likely to appear and be developed in discussions with peers rather than in individual interviews. The semi-structured format allowed us to provide the general setting of the discussions, introducing topics, providing prompts and follow-up questions, while allowing for unforeseen topics to be brought up and deliberated by participants. Eight semi-structured focus groups with a total of 45 participants from the general public were conducted in two Swedish cities of different size: Stockholm, the capital of Sweden with a population of approximately one million, and Gavle, a city of about 100000 inhabitants.

In order to get a diverse representation in terms of age, gender, ethnicity and education, the participants were recruited by the data collection consultancy company Norstat through randomised telephone calls. In addition, a small number of participants was recruited from Norstat's panels comprised of some 70,000 Swedish residents. Previous studies [e.g. Vetenskap \& Allmänhet, 2019b; Lakomý et al., 2018] have shown level of education to be an important, consistent and determining factor in relation to confidence in research. To this end, half of the focus groups - two in each city - were composed of participants with a high school diploma or less, and the other half consisted of participants with tertiary education experience. The data collection took place in October/November 2015.

One facilitator and one observer participated in each focus group, which on average lasted around two hours. As a basis for the discussions, the facilitator used an interview guide containing the topics to be introduced for discussion. The core topic was confidence in research and researchers and how this relates to (i) different research fields, (ii) how the research is being performed and by whom, (iii) how the research is funded.

The focus groups were audio-visually recorded and later transcribed. The transcripts were subjected to thematic analysis [Braun and Clarke, 2006]. Using the analytical tool Dedoose, ${ }^{1}$ the inductive process was based on generating initial codes that were later organised into themes.

At the beginning of each focus group, the participants were asked to reflect on their levels of confidence in research and researchers, respectively, and to respond on a sheet of paper containing a five point likert-scale from very low confidence to very high confidence [identical with the questions and response options used in Vetenskap \& Allmänhet, 2019b]. The answers were used as prompts to commence discussions among the participants. At the end of the focus group, the participants were asked to revisit their answers and to reflect on any perceived difference as compared to the stated levels at the beginning of the discussions.

\footnotetext{
${ }^{1}$ Dedoose Version 7.0.23, http:/ / www.dedoose.com.
} 
Table 1. Focus group participants by age, gender and geographic location.

\begin{tabular}{|l|rr|rr|}
\hline & \multicolumn{2}{|c|}{ Stockholm } & \multicolumn{2}{c|}{ Gavle } \\
\hline & Low education & High education & Low education & High education \\
\hline Women & 7 & 7 & 5 & 7 \\
Men & 5 & 5 & 3 & 6 \\
Age span & $18-65$ & $24-77$ & $18-54$ & $23-72$ \\
Median age & 42 & 45 & 27 & 52 \\
\hline
\end{tabular}

Results

As can be seen in Table 2, the participants' perceived levels of confidence in research and researchers before the focus group session was generally high. A large majority stated having a very or fairly high confidence in their forms, with a slightly higher confidence in research than in researchers. Only one participant claimed to have a fairly low confidence in research. While no participants selected the very low confidence option for neither research nor researchers, two did not mark their confidence levels in a legible way.

Table 2. Levels of confidence in research and researchers, respectively, as stated by participants before the focus group discussion (numbers indicate legible responses in each group).

\begin{tabular}{|c|c|c|c|c|c|}
\hline & Very high & Fairly high & $\begin{array}{l}\text { Neither high } \\
\text { nor low }\end{array}$ & Fairly low & Very low \\
\hline \multicolumn{6}{|l|}{ Stockholm } \\
\hline \multirow{2}{*}{$\begin{array}{l}\text { Non-tertiary } \\
\text { education }\end{array}$} & 1 (research) & 10 (research) & 1 (research) & 0 (research) & 0 (research) \\
\hline & 0 (researcher) & 10 (researcher) & 2 (researcher) & 0 (researcher) & 0 (researcher) \\
\hline \multirow{2}{*}{$\begin{array}{l}\text { Tertiary } \\
\text { education }\end{array}$} & 2 (research) & 9 (research) & 0 (research) & 0 (research) & 0 (research) \\
\hline & 1 (res & 7 (researcher) & 3 (researcher) & 0 (researcher) & 0 (researcher) \\
\hline \multicolumn{6}{|l|}{ Gävle } \\
\hline \multirow{2}{*}{$\begin{array}{l}\text { Non-tertiary } \\
\text { education }\end{array}$} & 3 (research) & 2 (research) & 1 (research) & 1 (research) & 0 (research) \\
\hline & 1 (researcher) & 4 (researcher) & 2 (researcher) & 0 (researcher) & 0 (researcher) \\
\hline \multirow{2}{*}{$\begin{array}{l}\text { Tertiary } \\
\text { education }\end{array}$} & 3 (research) & 9 (research) & 1 (research) & 0 (research) & 0 (research) \\
\hline & 2 (researcher) & 6 (researcher) & 6 (researcher) & 0 (researcher) & 0 (researcher) \\
\hline \multirow{2}{*}{ Sum } & 9 (research) & 30 (research) & 3 (research) & 1 (research) & 0 (research) \\
\hline & 4 (researcher) & 27 (researcher) & 13 (researcher) & 0 (researcher) & 0 (researcher) \\
\hline
\end{tabular}

When reflecting on the forms after the focus group session, most participants said that their confidence in research had not changed. At the same time, some felt that their confidence in researchers had been lowered after the discussions. This finding is elaborated upon under the "Person" section, below. Overall, the discussions made obvious that the participants' confidence in medicine and the natural sciences was substantially higher than their confidence in the humanities and the social sciences.

Four overarching themes, with regard to what influences confidence in research, emerged from the analysis of the transcribed material from the focus group discussions: 
1 Person (the individual who performs the research, i.e. the researcher)

2 Process (how the research is performed)

3 Product (the results and their usefulness)

4 Presentation (how the research is communicated)

Each of these four themes contain narratives with potential to either promote or lower confidence in research. Below, each theme is elaborated on and illustrated with quotes from the focus group discussions.

Person

This theme concerns the individuals who carry out the research - the researchers/scientists. Several narratives expressed by the participants described researchers in positive ways. Here, researchers were seen as hard-working, competent, experienced experts who are passionate about their work, who demonstrate an understanding of the societal context that they are part of, and who are able to explain their work to "normal" people. Such narratives contributed to promoting confidence in research. If the researcher was employed by a trustworthy organisation, such as a university, this also had a positive effect on confidence. At the same time, negative narratives were also part of the discussions. These were to a large degree the counter-parts of the positive narratives. Hence researchers could be seen as narrow-minded, disconnected and oblivious as to what is going on in the rest of society, as engaging in misconduct for personal gain — or to fulfill financial motives of their employers - overestimating their own results, and being unable to explain what they are doing to normal people. As could be expected, such narratives decreased confidence in research.

\section{Tertiary education group, Stockholm:}

"Something that can really lower [confidence] is if the person is being interviewed on $T V$ and says weird things or seems stupid, or doesn't have a clue about what's going on in society. You realise that you don't trust the person because he or she doesn't seem clever or educated. Then I don't trust his results either." Woman 46 years.

\section{Non-tertiary education group, Gavle:}

"I have a pretty high confidence in scientists. For one thing, it's most often highly educated people who are working with research and that's what first came to my mind, and then they've solved some things that one cannot even imagine how it's possible. One should have a lot of confidence in that." Man 20 years

\section{Non-tertiary education group, Stockholm:}

\footnotetext{
"Whoever is doing research, regardless if it's on an Indian tribe in the Amazon or whatever you're doing, you're probably very passionate about it. Research isn't something that's being done in a day. You have to be passionate about it regardless if it's fruit flies or whatever it is." Woman 41 years
} 
Tertiary education group, Stockholm:

\begin{abstract}
"If I'm to elaborate on it, if I'm to be frank, I think there are some oddballs who cling to ideas that are completely unreasonable. You have to put up with things like that in all trades, but sometimes it's very important that you can change your mind." Woman 73 years
\end{abstract}

Some of the personality traits brought up in the discussions were typical negative and positive stereotypes often associated with how scientists are portrayed in popular media [e.g. Haynes, 2003]. Applying Haynes' classification of stereotypes to our material, researchers were, on the positive side, described as the "noble scientist" - a hero or saviour of society; and on the negative side as the "inhuman researcher" or the "foolish scientist" [Haynes, 2003]. However, the discussions also indicated that a certain amount of eccentricity or quirkiness was allowed on the part of the researcher, without affecting confidence in his or her capacity as a professional scientist.

\title{
Tertiary education group, Stockholm:
}

\begin{abstract}
"It's not just if you say things in an awkward way, if you're stuttering, pale and boring. Then it's more like you get your image of a researcher confirmed - that it's this nerd in a lab coat. That was not what I meant, but rather that when it's someone who doesn't have a feeling for society and holds weird opinions. Then I'm likely to believe that the research is coloured by that." Woman 46 years
\end{abstract}

Often the stereotypes were based on impressions that the participants had gotten through observing researchers in the mass media. But personal encounters were also described.

\section{Non-tertiary education group, Stockholm:}

\author{
"I was at a wedding where a cancer professor got married and he had lots of colleagues \\ there. They were damn good scientists, but socially many of them were complete \\ oddballs." Man 48 years
}

As mentioned above, we recorded a decrease in confidence in researchers in some groups as we, at the end of the session, returned to the participants' initial confidence estimations. We interpret this phenomenon as a result of the group discussion per se. Reflections on the researcher as a person, and on factors that may promote or lower confidence in his/her work, seemingly led to the persona of the researcher as an always-objective genius to develop into a more nuanced character - an ordinary person. And like other ordinary persons, the researcher could succumb to human drives and agendas such as greed, laziness, vanity. 


\title{
Non-tertiary education group, Gavle:
}

\author{
"Rounding up, would you place your marks [indicating confidence in research and \\ researchers, respectively] differently after our discussions?" Moderator \\ "I think so. I would change mine to 'neither high nor low' [confidence] for researchers. \\ Before, I had selected 'fairly high'." Woman 54 years \\ "So, you have become slightly more doubtful?" Moderator \\ "Yes, through the discussion. There is a lot of wangling going on, that we are not \\ aware of; a lot that we do not find out. A lot of money is being spent on unnecessary \\ things." Woman 54 years
}

The discussions also brought to the surface uncertainties of what qualifications researchers need have, and what it means for something to be "scientific". This uncertainty was also seen to have a confidence-lowering effect. We saw no such confidence-lowering effect on the participants' confidence in research after the discussions.

\section{Tertiary education group, Stockholm:}

\begin{abstract}
"I'm not sure what you need to be a scientist, but it feels as if anyone could be a scientist. You often hear in commercials how "scientists have produced this toothpaste in Switzerland", and so on. But who is that person? It could be anyone, and then it's exploited a lot in the media. So, I have a quite low confidence, really. It's such a vague title. I think I need to look up what it takes to be a scientist." Woman 35 years,
\end{abstract}

A handful of researchers were mentioned by name, such as the late physicist Stephen Hawking, and the late epidemiologist Hans Rosling, but discussions on individual researchers were scarce in all groups. And while no mentions were made of gender in the discussions, all researchers mentioned by name were men. It is reasonable to assume that this to a large extent is an effect of the dominance of male researchers in the mass media [e.g. Vetenskap \& Allmänhet, 2019a].

\section{Process}

In the discussions, certain characteristics of the research process were seen to have a profound effect on confidence in research. Transparency in the research process was such a factor, where goals, aims, results and any financial or other interests that could have had an impact on the results needed to be openly declared to inspire confidence. Among sceptical narratives, many were centred upon research conducted by corporations with a hidden agenda, often of financial nature. Sometimes the corporation was described as the part at fault, forcing or encouraging researchers to adjust results in line with the company's wishes. Other times, it was the individual researcher who, without being ordered by his/her employer, took short-cuts or fabricated results for personal gains. 
Tertiary education group, Stockholm:

"I think a lot of the research is controlled by interests. If you look at the dairy industry, they're doing research on how great it is with milk and calcium. It's not always very neutral. Money from big industries play an important part, and they can control a lot." Woman 35 years

\title{
Tertiary education group, Stockholm:
}

"I feel that there are lobby groups. I'm sure the pharmaceutical industry can use lobby groups to indicate things, in order to sell a certain type of pill." Man 24 years

\section{Non-tertiary education group, Stockholm:}

"A researcher can be employed by a company because they want facts that point in a certain direction. You can pay for research to get the results that you want. I have more confidence in research than in researchers. I've never thought about this before, but it's a rather interesting thought." Woman 43 years

Making money on research was not frowned upon per se, as was seen by the high confidence placed in medical research, but if financial interests were considered to affect results, this had a negative impact on confidence. In this respect, the humanities and the social sciences were at an advantage, as participants found it unlikely that research in these fields could have any financial or other agendas - as compared to, for example, a new medicine.

\section{Tertiary education group, Stockholm:}

\begin{abstract}
It's not bad to make money, but there's a negative side to it. You can choose profession or field depending on where you make the most money. Naturally, it's good to get a reward if you've done something good, but it's negative if someone says, "you'll get two million if you get this result", then you'll be doing it for the money and not for the research itself. The more money it involves, the more greedy people will be drawn to it. Woman 28 years
\end{abstract}

Large studies, involving substantial amounts of data/observations, and research that was described as scientific/objective with regard to how it was performed by the researcher also inspired confidence in research. Another aspect was how "difficult" the research was seen to be, where more difficult research (e.g. physics) inspired more confidence than research that addressed or analysed "the obvious". Both with regard to the objectivity of the research, and its level of difficulty, there was a strong tendency to view the natural sciences and medicine as superior to the humanities and social sciences.

Some participants argued that they had more confidence in research on topics in which they had a personal understanding. This, they felt, allowed them to make a more qualified assessment of the credibility of the research. Others claimed that they had more confidence in topics where they had no personal knowledge, and thus had to rely on what the researcher was telling them. 
Tertiary education group, Stockholm:

\author{
"One has more trust in research topics that one doesn't know so much about." Woman \\ 32 years \\ "I feel it's the other way around." Man 44 years \\ "I feel that as I don't have the necessary knowledge on the topic, I need to trust the \\ professionals." Woman 32 years \\ "But for me it's the other way around. That makes me more critical towards the topic \\ and makes me want to learn more, to find out how things really are." Man 44 years
}

\title{
Product
}

The product theme encompasses narratives about the output of the research: the results. Societal benefit/impact of the results was a highly influential factor with regard to the participants confidence in different areas of research, where medicine (e.g. cure for cancer) had a clear advantage over the humanities and the social sciences, where societal relevance often was perceived as less clear. In the discussions, this was manifested by recurring stories of medical research that cures diseases (confidence-promoting) and obscure humanities/social sciences research with no societal use (confidence-decreasing). When weighing in the confidence-promoting less commercial nature of research within the humanities and social sciences, as discussed under the "Process" theme, it was quite clear that the outcomes of the research were given a much larger weight in shaping the overall confidence in the different areas of research.

\section{Non-tertiary education group, Stockholm:}

"Cancer research is highly beneficial! It's high on my list. Other sorts of research you might be able to skip, because it isn't useful for anyone. There is probably research being conducted that is of no use, nor forwarding for society." Man 65 years

\section{Tertiary education group, Stockholm:}

\footnotetext{
"There are so many fields of research. Some things that you hear about seem pretty meaningless, you're doing research on things that are obvious. Then there are other things that are a lot more essential. I'm thinking about medical science and that kind of research." Man 74 years

"Do you have any examples of non-essential research?" Woman 28 years

"I'm thinking about when I studied modern languages at university, then there were researchers at my institution who were doing a PhD on the lisp sound in medieval English. For me it was a pretty strange subject. But it was very serious for those who were working on it." Man 74 years
}

Interestingly, while many narratives emphasized the importance of research providing concrete benefit for society, discussions also showed clear support for the necessity of research driven by curiosity - of fundamental or "blue skies" research, as it was acknowledged that it is impossible to predict what possible 
future benefits today's research results may bring. Some participants also described how they enjoyed finding out scientific facts about ordinary, non-important, things. This could be seen as an indication that interesting may not always equal important for the individual, when it comes to research interests.

\section{Non-tertiary education group, Gavle:}

"Personally I think it's fun with such little things that you notice in everyday life, but are unsure about and they don't really mean anything special, but are just there. Then it's fun to find answers to such things. It's fun that they do curiosity-based research." Woman 29 years

Another element in the Product theme is clarity, as clearly defined results and observable benefits promote confidence, and vague or obvious results decrease confidence. Again, often to the favour of medicine and the natural sciences. In cases where there is scientific consensus about a certain result - i.e. if the results are publicly acknowledged and agreed upon by many researchers - this inspires confidence, whereas differing opinions among researchers, as well as contradictory results, were said to decrease confidence. In many groups, this was in part displayed through recurring discussions on nutrition. Participants frequently used nutrition as an example of a low-confidence research field, due to contradictory results being reported in the mass media. At the same time, nutrition was also brought up in discussions about research findings that the participants had personally embraced in terms of behavioural change.

\section{Non-tertiary education group, Stockholm:}

"One day it's great to drink milk, the other it's not. If that's applied research, then I don't have a lot of confidence in it." Woman 60 years, lower education group, Stockholm.

\section{Tertiary education group, Stockholm:}

"If I'm standing in the lunch restaurant, about to pick ten different vegetables, I know that broccoli counteracts cancer and helps cells to repair themselves, so I eat broccoli for lunch every day." Woman 46 years

\section{Presentation}

The presentation theme includes narratives on how the research is communicated. Some are closely related to, and may overlap with, factors of the Person theme as they involve the researcher as a communicator.

Research that is given high visibility in the mass media signals that the research is important, which thus contributes to higher confidence. As the natural sciences, and medicine in particular, are generally given substantially more space in the mass media's coverage of research news than the humanities and the social 
sciences, this visibility most likely adds to promoting confidence in medicine and the natural sciences [Pellechia, 1997; Bucchi and Mazzolini, 2003; Vetenskap \& Allmänhet, 2019a]. This connection between coverage and public perception of importance was spontaneously reflected upon in one group.

\title{
Non-tertiary education group, Gavle:
}

\author{
"Like cancer, heart disease and things like that, those are more important things [to do \\ research on]." Woman 54 years \\ "But perhaps they only seem important to us because they have been reported in the \\ media for so many years." Man 29 years
}

While the message needs to be clear and entertaining enough to attract attention and keep the reader/listener/viewer interested, it was equally important for research communicators to not be too entertaining, or they would be seen as unreliable and superficial.

\section{Non-tertiary education group, Stockholm:}

\begin{abstract}
"Some research is mostly about statistics. Others have discovered sensible laws that you can relate to. If a researcher should be monkeying around on TV when he's talking about his results, you wouldn't believe it. He has to possess a certain degree of seriousness!" Woman 56 years
\end{abstract}

But how to communicate complex scientific issues to a world with an ever-shortening span of attention? This question was debated as several groups touched on the challenges of communicating research to an online society. There were concerns that developments towards shallower and shorter online communications would lead to a decline in the population's ability to understand science and research.

\section{Tertiary education group, Gavle:}

\footnotetext{
"Researchers definitely need to adapt according to society, but the question is how far they should go. If you're writing an article for a medical journal, it's pretty comprehensive. Then you have to redo it to send it to Aftonbladet [Swedish evening paper], but in a few years, it won't even be Aftonbladet, but Twitter, Instagram or something else. How low should you sink? At the end, there'll be no knowledge at all. How is anyone supposed to be able to do research when the next generation won't even be able to read a research article?" Woman 32 years,
}

When researchers communicate their research, they need to express themselves in a way that can be understood by "ordinary people", show that they understand the societal context of their work, and are aware of what is going on in ordinary people's lives. The late epidemiologist Hans Rosling was praised by several groups for his ability to make complex issues understandable and captivating. 
Tertiary education group, Gavle:

\begin{abstract}
"You have to be pedagogical like Rosling! That's the solution!" Man 66 years,
"Yes, he's understood how people work, like when he shows how things are with the Syrian refugees, using pieces of plastic to show the distribution. You almost have to do like that for the masses to understand, since we're unfortunately too dumb to grasp it unless it's made very clear to us. He does this very well and doesn't talk over people's heads, but makes it clear and concise." Woman 32 years
\end{abstract}

Discussion and conclusions
The role played by narratives in shaping confidence or understanding is not fully understood. However, it seems as though narratives do not merely make an efficient vehicle for transmitting information, but are a crucial part of the meaning-making process that continuously shapes our worldview [e.g. Goodson et al., 2010; Jones and Song, 2013]. Thus, by exploring narratives expressed in discussions on confidence in research we might reveal clues both for explaining present confidence levels, as well as for designing communication strategies to foster confidence in science.

As expected, many previously described dimensions of trust and confidence can be found in the narratives of our four themes - Person, Process, Product and Presentation. For example, applying the dimensions for epistemic trust described by Hendriks, Kienhues and Bromme [2015], Expertise was an important part of the Person and Presentation themes, whereas Integrity and Benevolence had a strong presence in all four themes [cf. Hendriks, Kienhues and Bromme, 2015].

The confidence-promoting and confidence-lowering narratives described in this study provide clues with regard to the interpretation of the varying confidence levels for different research areas as measured in the Swedish public surveys (Figure 1). Considering the highest-ranking area - medicine - the focus group discussions describe it as providing society with clear and useful benefits in the shape of medicines and new treatments (product). It often involves large studies, can be seen as "difficult", and poses research questions that can be objectively verified or falsified (positive process aspects). However, medical research may also involve private companies and financial interests, which are potential confidence-lowering factors. The medical researchers are seen as competent experts (positive person narrative). It should be noted that the Macchiarini scandal ${ }^{2}$ had not yet been revealed at the time of the focus group discussions, which may otherwise have led to more negative narratives (e.g. fraudulent behaviour) in relation to medical research. Interesting topics, clear messages and high visibility in the mass media were positive presentation narratives, which often involved medical research.

Looking at research within the humanities, which has the lowest confidence-levels in the quantitative surveys, the narratives take on different shapes. The product is described in terms of opaque results of doubtful usefulness for society. As it seemed to be unclear to participants how research within the humanities was conducted, the process was non-transparent, and seen to be heavily influenced by the researcher's personal interpretations. Dominating narratives about the

\footnotetext{
${ }^{2}$ Paolo Macchiarini was a visiting professor at Karolinska Institutet 2010-2016, and was in 2018 found guilty of research misconduct (see e.g. https:/ / ki.se/en/news/the-macchiarini-case-timeline).
} 
humanities described the field as aimless, or adrift (process). Results were described as subjective, coloured by the researchers' opinions (product), and made-up titles for humanities research projects were sometimes used as examples of research of doubtful benefit, such as "nomad life in the Andes 5000 BC". Despite these opinions, when discussing research that the participants would be interested in taking part in themselves, topics within the humanities or social sciences were often brought up. Some confidence-promoting narratives also touched upon a lack of financial interests in the humanities (process), and that researchers need to be driven by their own passion (person).

Considering the two examples mentioned above, parallel narratives may be seen as having different relative impact on confidence. For instance, comparing product and process narratives for medicine and the humanities, the confidence-promoting narrative of medical research as important for future health (product) might be seen as a competing narrative to the presence of confidence-decreasing financial interests (process); while in the case of humanities, ambiguous results with a lack of societal benefit (product) was a negative narrative that seemed to have a larger influence on the participants' confidence, than the absence of financial bias (process).

In our focus groups, nutrition was brought up as a research area in which participants had very low confidence. At the same time, some of them had apparently adapted certain personal behaviours according to such research results. This inherently raises a question: could it be that confidence in research is not a prerequisite for influencing behavioural change? Considering that the confidence - influence assumption is the basis of a fair amount of research (see Context) and many science communication initiatives, this is an intriguing question. As the focus group participants all considered themselves as having a very high or a relatively high confidence in research in general, our interpretation is that this wider confidence in research as a concept may be more decisive than a low confidence in a specific field. Other key elements are most likely a close connection between nutrition and personal health, as well as from whom they learned of the research, and for whom they made the change in behaviour. One of the participants described how she had begun to rinse her rice before cooking it, having been instructed to do so by her grown daughter. Another, based on the same research results (about rice containing arsenic), had stopped giving her young child rice cookies "just in case".

The seemingly paradoxical finding that some participants claimed that personal knowledge about a research area increased their confidence in this area, while others felt that they had more confidence in areas that they knew nothing about, could be seen as adding to the critique against the deficit model, as it suggests that there is no clear connection between knowledge and attitudes to science.

Given the exploratory nature of the presented research, our findings do not claim to be exhaustive. Focus groups were considered a relevant method for pursuing our objectives and resulted in several findings of interest. Nevertheless, there are also limitations with the method. Among these are that the discussions are strongly affected by the composition of participants. Even though facilitators were present to ensure an open and relaxed atmosphere, the presence of others may affect participants' openness, honesty and associations. In light of this, themes that did not emerge in the discussions, such as Felt and Fochler's [2013] finding that the 
narrative of research as continuously exciting and successful decreases confidence, should not be interpreted as if these do not play a role in the shaping of confidence among our participants. Another possible limitation is that a majority of the participants initially expressed fairly or very high confidence in research. This may not be surprising, as all participants had agreed to take part in a focus group session about research and researchers, which could be taken as an indication of an interest in, and possibly a positive view on, the topic. Having a larger proportion of participants with explicitly low confidence would not reflect the composition in society at large, but would possibly give rise to partly different narratives.

The study was performed in Sweden, with Swedish participants, and the results should be interpreted according to their national context. Even though many countries share a relatively high level of confidence towards research [Gallup, 2019], data from the World Values Survey indicate that Sweden has very high levels of interpersonal trust compared to other nations [Inglehart et al., 2014]. According to data from OECD, Sweden also have higher trust in public institutions than the European average [OECD, 2015]. Whether such cultural differences may give rise to differing narratives on confidence in research in other national settings presents an intriguing case for future research.

In summary, we find several recurring narratives that seem to have an impact on public confidence in research. The factors identified in this study provide insights as to why certain research areas consistently display higher confidence levels than others. Future research could further explore these narratives and their effects in qualitative and quantitative settings. For instance, experimental studies that compare the effect of different narratives in communications about different fields of research, presents an intriguing approach. This may contribute not only to an increased understanding of how public confidence is formed, but also to how researchers in practice can adapt communication activities for greater societal understanding and impact.

Funding

The project was funded by the Swedish Foundation for Humanities and Social Sciences (Riksbankens Jubileumsfond) and the Anne-Marie and Gustaf Anders Foundation.

References

Allum, N., Sturgis, P., Tabourazi, D. and Brunton-Smith, I. (2008). 'Science knowledge and attitudes across cultures: a meta-analysis'. Public Understanding of Science 17 (1), pp. 35-54. https: //doi .org/10.1177/0963662506070159.

Braun, V. and Clarke, V. (2006). 'Using thematic analysis in psychology'. Qualitative Research in Psychology 3 (2), pp. 77-101. https://doi.org/10.1191/1478088706qp063oa.

Bucchi, M. and Mazzolini, R. (2003). 'Big Science, little news: science coverage in the Italian daily press, 1946-1997'. Public Understanding Science 12, pp. 7-23. https://doi.org/10.1177/0963662503012001413.

Castell, S., Charlton, A., Clemence, M., Pettigrew, N., Pope, S., Quigley, A., Shah, J. N. and Silman, T. (2014). Public attitudes to science 2014: main report. URL: https://assets.publishing.service.gov.uk/government/uploads/sys tem/uploads/attachment_data/file/348830/bis-14-p111-public-attitude s-to-science-2014-main.pdf. 
Dahlstrom, M. F. (2014). 'Using narratives and storytelling to communicate science with nonexpert audiences'. Proceedings of the National Academy of Sciences 111 (Supplement 4), pp. 13614-13620.

https://doi.org/10.1073/pnas.1320645111.

Dierkes, M. and von Grote, C. (2005). Between understanding and trust: the public, science and technology. U.K.: Routledge.

Felt, U. and Fochler, M. (2013). 'What science stories do: rethinking the multiple consequences of intensified science communication'. In: Science communication today. International perspectives, issues and strategies. Ed. by P. Baranger and B. Schiele. Paris, France: CNRS Editions.

Füchslin, T., Schäfer, M. S. and Metag, J. (2018). 'A short survey instrument to segment populations according to their attitudes toward science. Scale development, optimization and assessment'. Environmental Communication 12 (8), pp. 1095-1108. https://doi .org/10.1080/17524032.2018.1461673.

Gallup (2019). Wellcome global monitor - first wave findings. URL: https://wellcome.ac.uk/reports/wellcome-global-monitor/2018.

Gauchat, G. (2012). 'Politicization of science in the public sphere: a study of public trust in the United States, 1974 to 2010'. American Sociological Review 77 (2), pp. 167-187. https://doi.org/10.1177/0003122412438225.

Goodson, I. F., Biesta, G., Tedder, M. and Adair, N. (2010). Narrative learning. U.K.: Routledge.

Haynes, R. (2003). 'From alchemy to artificial intelligence: stereotypes of the scientist in western literature'. Public Understanding of Science 12 (3), pp. 243-253. https://doi.org/10.1177/0963662503123003.

Hendriks, F., Kienhues, D. and Bromme, R. (2015). 'Measuring Laypeople's Trust in Experts in a Digital Age: The Muenster Epistemic Trustworthiness Inventory (METI)'. PLOS ONE 10 (10), e0139309.

https://doi.org/10.1371/journal.pone.0139309.

Hinyard, L. J. and Kreuter, M. W. (2007). 'Using Narrative Communication as a Tool for Health Behavior Change: A Conceptual, Theoretical, and Empirical Overview'. Health Education \& Behavior 34 (5), pp. 777-792. https://doi.org/10.1177/1090198106291963.

Inglehart, R. C., Haerpfer, A., Moreno, C., Welzel, K., Kizilova, J., Diez-Medrano, M., Lagos, P., Norris, E. and Puranen, P., eds. (2014). World values survey: round six - country-pooled datafile version. Madrid, Spain: JD Systems Institute.

URL: http: //www . worldvaluessurvey . org/WVSDocumentationWV6 . jsp.

Johnson, B. B. (1999). 'Exploring dimensionality in the origins of hazard-related trust'. Journal of Risk Research 2 (4), pp. 325-354. https://doi.org/10.1080/136698799376763.

Jones, M. D. and Song, G. (2013). 'Making sense of climate change: how story frames shape cognition'. Political Psychology 35 (4), pp. 447-476. https://doi.org/10.1111/pops.12057.

Kahan, D. M., Jenkins-Smith, H. and Braman, D. (2011). 'Cultural cognition of scientific consensus'. Journal of Risk Research 14 (2), pp. 147-174. https://doi.org/10.1080/13669877.2010.511246. 
Lakomý, M., Bohlin, G., Hlavová, R., Macháčková, H., Bergman, M. and Lindholm, M. (2018). Public attitudes to life sciences research in six European countries. (ORION project Deliverable No. 2.3). Stockholm, Sweden.

Luhmann, N. (2000). 'Familiarity, confidence, trust: problems and alternatives'. In: Trust: making and breaking cooperative relations. Electronic edition. Oxford, U.K.: Department of Sociology, University of Oxford. Chap. 6, pp. 94-107.

Malka, A., Krosnick, J. A. and Langer, G. (2009). 'The association of knowledge with concern about global warming: trusted information sources shape public thinking'. Risk Analysis: An International Journal 29 (5), pp. 633-647. https://doi.org/10.1111/j.1539-6924.2009.01220.x.

Master, Z. and Resnik, D. B. (2013). 'Hype and public trust in science'. Science and Engineering Ethics 19 (2), pp. 321-335. https://doi.org/10.1007/s11948-011-9327-6.

OECD (2015). How's life? 2015: measuring well-being. Paris, France: OECD Publishing.

Pellechia, M. (1997). 'Trends in Science Coverage: A Content Analysis of Three US Newspapers'. Public Understanding of Science 6, pp. 49-68. https://doi.org/10.1088/0963-6625/6/1/004.

Peters, R. G., Covello, V. T. and McCallum, D. B. (1997). 'The determinants of trust and credibility in environmental risk communication: an empirical study'. Risk Analysis 17 (1), pp. 43-54. https://doi.org/10.1111/j.1539-6924.1997.tb00842.x.

Resnik, D. B. (2011). 'Scientific research and the public trust'. Science and Engineering Ethics 17 (3), pp. 399-409. https://doi.org/10.1007/s11948-010-9210-x.

Schäfer, M. S., Füchslin, T., Metag, J., Kristiansen, S. and Rauchfleisch, A. (2018). 'The different audiences of science communication: a segmentation analysis of the Swiss population's perceptions of science and their information and media use patterns'. Public Understanding of Science 27 (7), pp. 836-856. https://doi.org/10.1177/0963662517752886.

Sperber, D., Clément, F., Heintz, C., Mascaro, O., Mercier, H., Origgi, G. and Wilson, D. (2010). 'Epistemic vigilance'. Mind \& Language 25 (4), pp. 359-393. https://doi.org/10.1111/j.1468-0017.2010.01394.x.

Vetenskap \& Allmänhet (2019a). Forskning i svensk press 1995-2015 — en innehållsanalys. [Research in the Swedish press 1995-2015 - a content analysis]. VA-rapport 2019:7. In press. Stockholm, Sweden.

- (2019b). Vetenskapen i Samhället — Resultat från SOM-undersökningen 2018. [Science in society - Results from the national SOM-survey 2018]. VA-rapport 2019:6. Stockholm, Sweden. journalism from Uppsala University. Current research projects include citizen science, digital civic literacy and mass media coverage of science.

E-mail: fredrik@v-a.se. 
Maria Lindholm served as Director of Research at VA (Public \& Science) from 2012 to 2018 [and was leading the initial phases of this study]. She is currently employed as Senior Analyst at the Swedish Research Council. Maria Lindholm holds a PhD in Language and Culture from Linköping University, Sweden, with a specific research interest in the communicative practices of the European Commission.

E-mail: maria.a.lindholm@gmail.com.

Gustav Bohlin is a researcher working at VA (Public \& Science) since 2017 and an affiliated researcher at the Department for Learning, Informatics, Management and Ethics (LIME) at Karolinska Institutet. He holds a PhD in Science Education from Linköping University, Sweden. His research interests encompass scientific literacy, public understanding of- and confidence in science as well as researchers' attitudes to communication. E-mail: gustav@v-a.se.

How to cite

Brounéus, F., Lindholm, M. and Bohlin, G. (2019). 'Telling it straight — a focus group study on narratives affecting public confidence in science'. JCOM 18 (05), A03. https:/ / doi.org/10.22323/2.18050203. 